\title{
Inhibition of reoxidation of direct reduced iron ( DRI) or sponge iron
}

\author{
Jaleel Kareem Ahmad \\ College of Materials Engineering, Babylon University, Babylon, Iraq
}

\section{Email address:}

Jaleel_kareem@yahoo.com

\section{To cite this article:}

Jaleel Kareem Ahmad. Inhibition of Reoxidation of Direct Reduced Iron ( DRI) or Sponge Iron. International Journal of Materials Science and Applications. Special Issue: Steel and Direct Reduced Iron (sponge Iron) Industry. Vol. 4, No. 2-1, 2015, pp. 7-10.

doi: $10.11648 /$ j.ijmsa.s.2015040201.12

\begin{abstract}
A method of inhibiting degeneration of direct reduced iron by immersing the iron ore, after it has been reduced, in molten wax for a period of time sufficient for the wax to cover completely the surface of the iron and to enter the pores in the surface of the iron. The iron is preferably in the form of pellets which are conveyed in mesh baskets which are themselves immersed in the wax. The wax is preferably paraffin wax at a temperature of between $110^{\circ}$ and $120^{\circ} \mathrm{C}$.
\end{abstract}

Keywords: Inhibition of Reoxidation, Waxing Process, Sponge Iron, Metallization, Fines

\section{Introduction}

The industry of direct reduced iron (DRI) is appeared at the end of 1967 by a mixican company called HYL (the union of iron and steel production companies) but this industry do not spread out side México, because the big international companies do not support that until the Midrex process (the union of American and German companies for production of iron and steel) is appeared at the end of 1975 ,then this process spread in Europe and Middle East .The spreading of this new technology is due:

1) Low grades iron ore are available only this makes high blast furnaces technology which used enriched iron oxide ore economically unacceptable. The industry of DRI depends on magnetic separation to concentrate iron oxide in the ore then reduce it .

2) DRI is sulfur and phosphorous-free both elements have bad results on the mechanical properties of the steel result from DRI

3) The increase of the scrap price in the international market result in increasing of the steel cost ,since the new technology used $80 \%$ DRI and 20\% scrap for steel production while classical process uses higher scrap percent or $100 \%$

4) It is possible easly to get steel with special specification

5) The shortage in the availability of coal suitable for coke production which is used in the production of iron in the classical technology in the developing countries
6) The availability of natural gas in low prices and it is one of the main material in the DRI industry .This gas used for production of reducing gases which convert iron oxides to free iron.This technology spread quickly and the international production reached 50 millions ton / year and expectable for more increasing and will be sell in the markets due:

a) Many DRI plants build near natural gas sources ,this will enhance to build plants with extra capacity than the requirements for melting furnaces, this lead to export the excess DRI quantity[1]

b) Since the increasing in the necessary need for the DRI, result in planning for commercial plant in the world

c) The difficult balance between the production of DRI and the electric furnaces consumption .

\section{Discussion}

\subsection{Properties of DRI}

DRI has high porosity resulting from the diffusion of gases which causes loses of oxygen from the crystal structure of the ore during reduction process . The porous structure of DRI is responsible for the name sponge iron for this material this porosity increasing the specific surface area of the sponge iron up to $4 \mathrm{~m}^{2} / \mathrm{g}$, this leeds to increasing in the water absorption by the sponge iron up to $16 \%$ by weight as well as increasing air absorption, thus increasing the ability of this material for reoxidation accompanied by heat and hydrogen 
evolved( explosive gas) enough for fire accidents in the store or in the transportation facility. Such fire is difficult to control by water. Although DRI pellets have been shipped in large quantities only during the last years ,there have already been a number of accidents.[2]

\subsection{Methods for Protection DRI from Reoxidation}

All known international methods depend on the insulation of DRI from the oxidized atmosphere .

1) Midrex method ( USA - Germany ) [3]

In this method DRI pellets are immersed in aqueous solution of sodium silicate (water glass), then the pellet pass through drying towers in which hot nitrogen gas is used ,then through cooling towers by using cold nitrogen gas. The disadvantages of this process are ,sodium silicate which coated the pellets is soluble in water, thus when DRI exposed to rain, the sodium coated film will soluble then DRI expose to reoxidation again , as well as sodium silicate form solid film which easy breaks or cracks during charging ,transportation , and discharging ,also sodium silicate has high melting temperature which consumes energy during melting of DRI in the electric are furnaces for steel making ,also the consumption of graphite electrodes and lining of the furnace higher than that for untreated DRI

2) Briquetting method (Germany- Japan )[4]

In this method DRI pellets milled to powder form by mechanical mills, then mix with water ,molass, and lime in certain percents to form a recipe, then the recipe push to special mould for making the briquette. This method depends on reducing the surface area of the iron that expose to the atmosphere .The surface of the briquette will oxidize when contact with the humidity .This process faced many mechanical problems in addition to its high consumption for lining, graphite electrodes and electrical energy comparing with untreated DRI during melting for steel making.

3) Storage under inert atmosphere (Germany ) [5]

This method depends on storage DRI under inert atmosphere by using inert gases such as nitrogen or carbon dioxide to protect DRI from air contact. This method need units for producing the requirement gas continuously .This method suitable for marine transport, in which ships provide with a gas units pushed to the DRI stores continuously .Such ships are of high cost comparing with their storage capability .The six stores which build in the iron and steel company in Basrah , Iraq with capacity of 48000 tons DRI cost 55 million dollars .But when DRI discharge from these stores expose again for reoxidation

4) Feuor mould method (USA ) [6]

This method introduced in the direct reduction symposium which held in Holland ,1983, organized by the economic committee of united Nation, Europe division .This method depends on drawing DRI from the reduction reactor (final reduction stage )at nearly $800{ }^{\circ} \mathrm{C}$ and crush to powder then molded as ingot to reduce its surface area which is exposed to atmosphere (the density of the molded DRI produced is $\left.\sim 5 \mathrm{~g} / \mathrm{cm}^{3}\right)$. This method can not be used for allready working plants. The inventor also pointed out that we must keep the percentage of evolved hydrogen due to the reoxidation of molds surface to be not exceed more than $4 \%$ in the air above the molds to avoid explosion, thus molds must be transport under good ventilation to avoid hydrogen accumulation. The inventor explains to get a good molds resistance to reoxidation, it must be produce DRI under certain specifications (he don't mention such specifications ). The disadvantages of this method are :molds consume higher electrical energy than untreated DRI during melting of DRI ,DRI molds without carbon (cooling stage in which carbon deposits on DRI omitted in this method, continuous feeding of DRI to the furnace by transport belts impossible in addition no economic benefits of making such molds in case of melting furnaces near to DRI production plants.

5) Jaleel process (Iraq) [7]

Iron and steel complex in Basrah, Iraq designed to produce 1200000 tons /year DRI or sponge iron according to HYL technology (Figure 1),800000tons for exporting via sea .In order to insure the transportation of this material, Iraqi Ministry of Industry and Minerals asks the international research canters, among these is the specialized institute for engineering industries (SIEI), Iraq. SIEI asks me for this problem, After one year of research taking in my consideration the post steps for steelmaking from DRI, an efficient method appeared called Waxing Process by using the local wax (Table 1). Tests show good efficiency for this material two tons of DRI is waxed, then melted in electric arc furnace for steelmaking. The results show good mechanical properties for the produced steel. An excellent transport test was carried out by transferring about 25 tons of treated (waxed by pilot plant Fig .2) DRI from Saudi iron and steel company (Saudi Arabia kingdom) to Baghdad /Iraq about $1200 \mathrm{~km}$ distance in open truck under raining weather was without any rise in the DRI temperature (thermometers immersed in the bulk of the DRI) , and no change in the degree of DRI metallization (free iron /total iron ) and without creation of fines (useless powder ). The price of DRI depends mainly on the above both of these characters. When fines percent exceed $2 \%$,DRI becomes unacceptable or sells with relatively low price. This method is the cheapest and the most efficient method in this field .It is registered as a patent in USA ,UK ,Mexico, and Japan .Jaleel process can be summarized by transferring the hot DRI from the last step (cooling step ) to the wax tank $\left(110-150{ }^{\circ} \mathrm{C}\right)$ and immersed for 3 seconds. The wax will closed the pores of the iron metal prevent air and humidity to contact the surface of the pellets.

Table 1. Specifications of Iraqi soft wax [8]

\begin{tabular}{ll}
\hline Specification & Value \\
\hline Penetration at $25^{\circ} \mathrm{C}$ & 34 \\
Oil content wt $\%$ max & 1.5 \\
Melting point ${ }^{\circ} \mathrm{C}$ & 48 \\
\hline
\end{tabular}




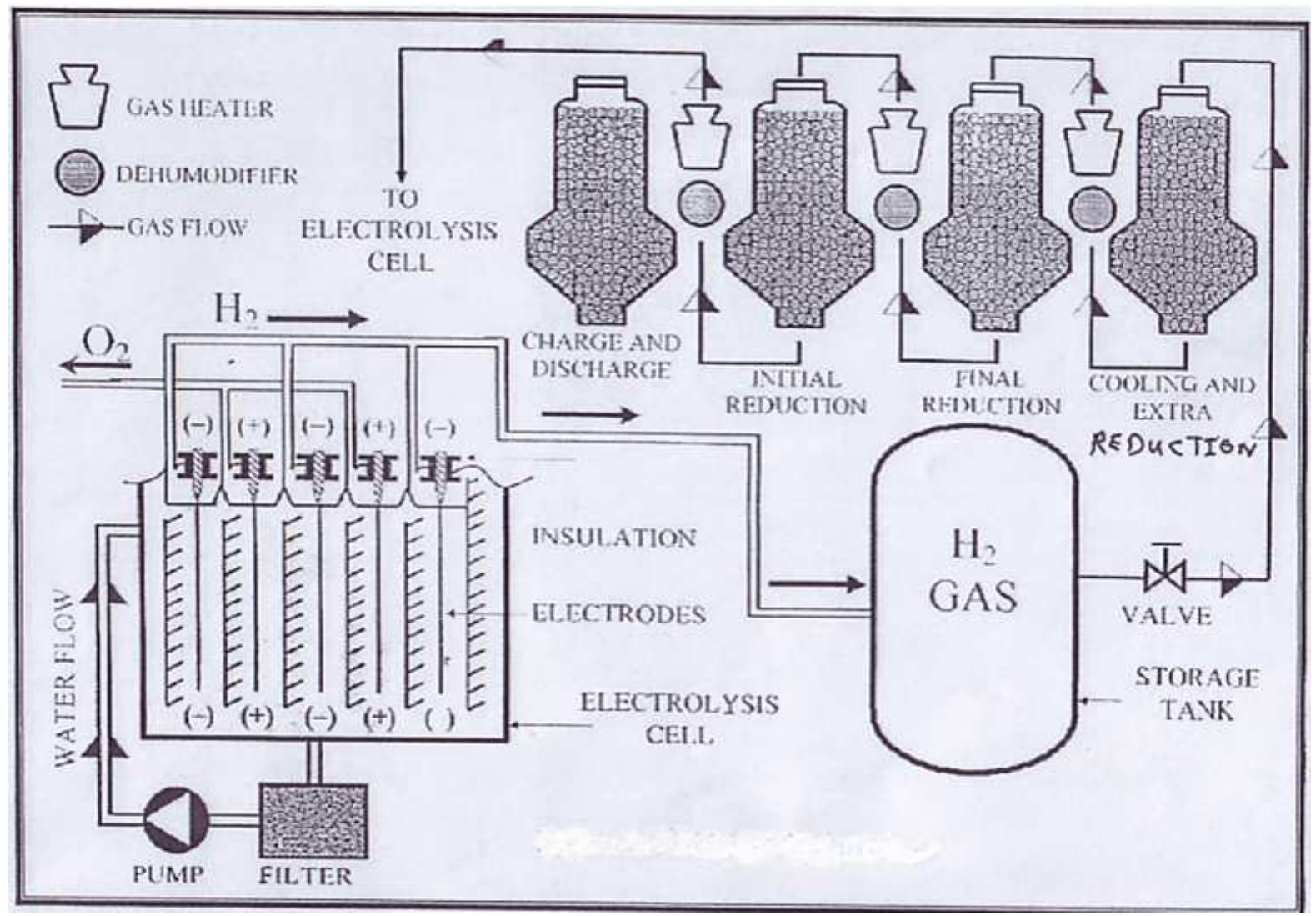

Fig. 1. Jaleel-HYL Process.

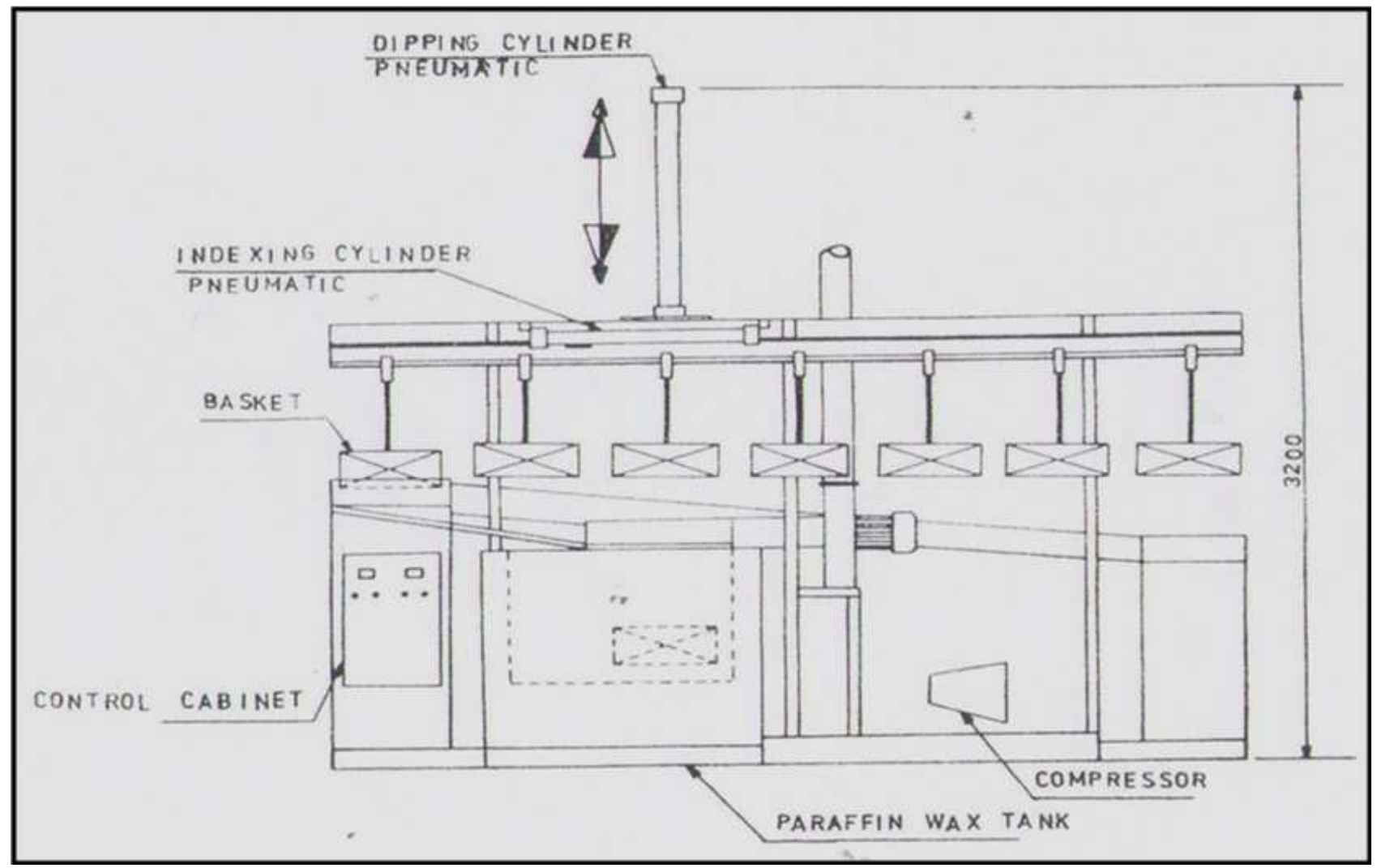

Fig. 2. Pilot Plant of Waxing Process for Sponge Iron. 


\subsection{Specifications of Waxed DRI}

The chemical specification of treated DRI is the same for untreated one, while the physical properties show in Table 2.

A comparison between waxing process and the others four methods for treatment of 800000 Tons / year DRI are summarized in Table 3.
Table 2. Specifications of untreated and treated DRI

\begin{tabular}{lll}
\hline Specification & Untreated DRI & Treated DRI \\
\hline 1) color & grey & dark grey \\
2)density ton $/ \mathrm{m}^{3}$ & 1.7 & 1.76 \\
3)water absorptivity $\%$ & 16 & zero \\
4)crushing pressure $\mathrm{kg} / \mathrm{cm}^{2}$ & $50-55$ & higher \\
5)cracking ability & high & very low \\
6)fines formation & high & nill \\
7) reoxidation ability & high & nill \\
\hline
\end{tabular}

Table 3. Comparison between waxing Process and the others for inhibition of reoxidation of 800000 tons/year DRI.

\begin{tabular}{|c|c|c|c|c|c|}
\hline Inhibition Method & $\begin{array}{l}\text { Consumption of } \\
\text { Material for Treated } \\
\text { one ton DRI }\end{array}$ & $\begin{array}{l}\text { Consumption of Electrical } \\
\text { Energy and Graphite Electrodes } \\
\text { Comparing with Untreated DRI }\end{array}$ & $\begin{array}{l}\text { Volume Density } \\
\text { of the Product } \\
\text { Ton } / \mathbf{m}^{3}\end{array}$ & $\begin{array}{l}\text { Water } \\
\text { Absorptivity } \\
\text { Wt } \%\end{array}$ & $\begin{array}{l}\text { Cost of the Project } \\
\text { / Million \$ }\end{array}$ \\
\hline $\begin{array}{l}\text { 1. Midrex (USA: } \\
\text { Germany ) }\end{array}$ & $\begin{array}{l}\text { Sodium silicate +water } \\
+ \text { nitrogen gas }\end{array}$ & More higher & $1.7-1.8$ & 8 & 12.9 \\
\hline $\begin{array}{l}\text { 2. Briquetting } \\
(\text { Germany -Japan })^{4}\end{array}$ & $\begin{array}{l}30 \mathrm{~kg} \text { molass }+20 \mathrm{~kg} \\
\text { lime }+170 \mathrm{~L} \text { water }\end{array}$ & More high & 2.3 & 7 & 25 \\
\hline $\begin{array}{l}\text { 3. Storage under inert } \\
\text { atmosphere } \\
(\text { Germany })^{5}\end{array}$ & Inert gas continuously & As for untreated & 1.7 & 15 & $\begin{array}{l}55 \text { for protection } \\
48000 \text { tons }\end{array}$ \\
\hline $\begin{array}{l}\text { 4. Feuor mold } \\
(\text { USA })^{6}\end{array}$ & --- & More high & 5 & 3 & $\begin{array}{l}\text { High cost need } \\
\text { mills and hammers }\end{array}$ \\
\hline $\begin{array}{l}\text { 5. Waxing process } \\
\text { ( Iraq ) }\end{array}$ & $60 \mathrm{~kg}$ wax & Less due to wax burning & $1.7-1.8$ & Zero & 2 \\
\hline
\end{tabular}

\section{References}

[1] Wolfgang Bietsch, Dr. -Ing, Direct Reduced Iron , British Foundryman, No.4, Vol. 71, (1978).

[2] A monthly review of transport incident and investigation (cargo ship),(1980).

[3] Technical and Budgetary capital cost information for a chamire corrosion. Inhibition process facility for Iraqi Ministry of Industry and Minerals / Organization of Industrial Design and Construction (1979).
[4] Iron briquetting plant study and recommendation, Sumitomo Heavy Industry (1987).

[5] project established in the iron and steel complex / Basrah , Iraq , (1985).

[6] Direct reduction symposium hold in Holland October (1983).

[7] Method of inhibiting degeneration of DRI ,U.S .Patent ,4692353 sep.8, (1987).

[8] Marketing Specifications of Iraqi Petroleum Products (2000). 